Kendall and Davison describe as a universal notation covering inorganic and organic chemistry and the chemistry of ions, free radicals and transition complexes ("Chemical Ciphering." Pp. 46. London : Royal Institute of Chemistry. 4s. net). The claims are thus even larger than those of Dr. Dyson, and a logical proof of the validity of the ciphering is appended, given the definition of a chemical species as a set of atoms individually stated, in which given pairs of these atoms are linked together by directed bonds and the net charge of the set, and of any discrete ions contained in it, are specified. The authors claim, moreover, that the system is expressed in the language of "basic chemistry", and in accord with modern trends in the theory of molecular structure. Whether the system can be mastered by a chemist in about an hour, as they also claim, is at least doubtful; and if they under-estimate the intellectual effort required to comprehend and apply their system, they have probably also under-estimated the willingness of chemists as a body to make such an effort.

That factor has to be weighed against whatever advantages a cipher notation can offer. The crucial question is the reality of those advantages. Is there, for example, any real hope that mechanical methods, such as punched cards, will be sufficiently widely used to justify the considerable finaneial investment involved. If universal use is probable, what are the real advantages of an entirely new cipher notation over some extension of the Richter-Stelzner formula system, for such purposes ? So far as systematics are concerned, what in economic terms are the advantages gained by a new system over the thoroughgoing application, for example, of the International Rules? A large part of the confusion and ambiguity in organic chemical nomenclature is due to the failure to apply those rules systematically and universally, and the very conservatism which has prevented such a relatively simple reform does not encourage optimism about the universal acceptance of systems involving so much larger an intellectual effort as well as a break with past practice.

\section{Nigerian Livestock Mission}

THE Secretary of State has sent a mission to visit West Africa to investigate the livestock industry in Nigeria and the Cameroons under British mandate, with particular reference to meat production. The Mission will also engage in discussion where necessary with the authorities of the neighbouring French territories on problems of mutual interest. The leader of the mission will be Sir Frank Ware, formerly animal husbandry commissioner to the Government of India, and the members will be Mr. Thomas Shaw, a director of Messrs. Zwanenberg-Organon, Ltd., and Mr. Gilbert Colville, who has special experience in the breeding-up of African cattle. Arrangements are being made for local officers of the veterinary, agricultural and geological departments to be attached to the mission. The mission will probably pay a further visit to West Africa in February or March to see the country and the cattle at the end of the dry season. During its first visit, the mission is spending a few days in the Gold Coast to discuss problems in connexion with the cattle industry there.

\section{Irrationality of the General Cubic Threefold}

REFERENCE has already been made in these columns (Nature, March 31, 1945, p. 385) to the proof by Prof. G. Fano, formerly of Turin, of a long. conjectured and important result in algebraic geometry. It has been known for nearly a century that the plane curve with equation $f_{3}(x, y)=0$, where $f_{3}$ denotes a cubic polynomial, is in general irrational, that is, its points cannot be set in one-to. one algebraic correspondence with the points of a line; in fact, its co-ordinates are expressible as elliptic functions of a single parameter. In contrast to this the general cubic surface, given by an equation $f_{3}(x, y, z)=0$, is rational, and the method of representing the surface biunivocally on a plane was obtained so long ago as 1866 . It was thus natural to inquire whether the general cubic threefold, given by an equation $f_{3}(x, y, z, t)=0$, is rational or not; the question posed by the Italian geometers some sixty years back long resisted all attempts at solution, and hence became one of the celebrated problems of geometry. In 1942, Fano (then in his seventieth year) at last established its irrationality; from Switzerland, where he was living as an exile, he communicated the discovery to the Pontifical Academy of Sciences, and this, after various delays, has now been published with cognate researches ("Commentationes", 11, 635; 1947). Fano's proof, though conceptually simple, involves considerable detail, and, in fact, marks the conclusion to a long chain of investigations, dating from 1907, when Fano showed that the general quartic threefold $f_{4}(x, y, z, t)$ $=0$ is irrational. It is interesting to note that the entire programme of the research was foreshadowed in a communication made to the International Mathematical Congress held at Bologna in 1928; this has now been carried out in all its details.

\section{The Little Ringed Plover in London}

IN 1947 little ringed plovers (Charadrius dubius curonicus) bred in the London area for the fourth year in succession, and there was a remarkable increase in numbers (British Birds, 41, No. 2; February, 1948). Eight nests were found, and four other broods seen. Because of the possibility that at least two pairs changed their sites after disturbance the exact number present is unknown; but there were certainly eleven and possibly fourteen pairs. Although the majority of the birds were again in Middlesex, there was an extension of range to three other counties and first breeding records were obtained for Essex (four pairs), Kent and Berkshire (one pair each). It is probable that the apparent sudden increase from four pairs in 1946 to a minimum of eleven pairs in 1947 is in part due to a lack of observation in previous years. It is curious that the known breeding range in Britain is, so far, restricted to Tring (where it bred in 1938 and 1944) and the London area (where it has bred annually since 1944). This may simply be due to lack of observation in other suitable places.

\section{Turkish Technical Review}

THE first issue (dated August 1948) has appeared of the Turkish Technical Review (Teknik Dergi), a monthly periodical which is claimed to be the first independent journal of that character published in Turkey apart from those coming from State institu. tions. It consists of forty-eight pages of text, with introductory notes by the Turkish Minister of Transport, by Prof. Tevfik Taylan, president of the Technical University of Istanbul, and the editors. There is an article on modern military tanks, another on jet motors and gas turbines, a description (translation) of a lathe with electronic control, an article (translation) on the application of plastics in chemical 